\title{
The use of opioids at the end of life: the knowledge level of Dutch physicians as a potential barrier to effective pain management
}

\author{
Mette L Rurup ${ }^{1,2}$, Christiaan A Rhodius ${ }^{2,3}$, Sander D Borgsteede ${ }^{4,5}$, Manon SA Boddaert ${ }^{2,3}$, Astrid GM Keijser ${ }^{1}$, \\ H Roeline W Pasman ${ }^{1,2}$, Bregje D Onwuteaka-Philipsen ${ }^{1,2^{*}}$
}

\begin{abstract}
Background: Pain is still one of the most frequently occurring symptoms at the end of life, although it can be treated satisfactorily in most cases if the physician has adequate knowledge. In the Netherlands, almost $60 \%$ of the patients with non-acute illnesses die at home where end of life care is coordinated by the general practitioner (GP); about 30\% die in hospitals (cared for by clinical specialists), and about 10\% in nursing homes (cared for by elderly care physicians).

The research question of this study is: what is the level of knowledge of Dutch physicians concerning pain management and the use of opioids at the end of life?
\end{abstract}

Methods: A written questionnaire was sent to a random sample of physicians of specialties most often involved in end of life care in the Netherlands. The questionnaire was completed by 406 physicians, response rate $41 \%$.

Results: Almost all physicians were aware of the most basal knowledge about opioids, e.g. that it is important for treatment purposes to distinguish nociceptive from neuropathic pain (97\%). Approximately half of the physicians (46\%) did not know that decreased renal function raises plasma concentration of morphine(-metabolites) and 34\% of the clinical specialists erroneously thought opioids are the favoured drug for palliative sedation.

Although 91\% knew that opioids titrated against pain do not shorten life, 10\% sometimes or often gave higher dosages than needed with the explicit aim to hasten death. About half felt sometimes or often pressured by relatives to hasten death by increasing opioiddosage.

The large majority (83\%) of physicians was interested in additional education about subjects related to the end of life, the most popular subject was opioid rotation (46\%).

Conclusions: Although the basic knowledge of physicians was adequate, there seemed to be a lack of knowledge in several areas, which can be a barrier for good pain management at the end of life. From this study four areas emerge, in which it seems likely that an improvement can improve the quality of pain management at the end of life for many patients in the Netherlands: 1)palliative sedation; 2)expected effect of opioids on survival; and 3) opioid rotation.

\section{Background}

Many factors may hamper optimal pain management such as patient nonadherence to drug therapy, underreporting of pain or miscommunication between patient and caregivers; from a healthcare provider perspective,

\footnotetext{
* Correspondence: b.philipsen@vumc.nl

'VU University Medical Center, EMGO Institute for Health and Care Research, Department of Public and Occupational Health, Amsterdam, The Netherlands

Full list of author information is available at the end of the article
}

inadequate assessment of pain, poor documentation and miscommunication may limit optimal pain management [1]. To achieve good patient care at the end of life, also adequate knowledge of pain management and opioids among physicians is essential. Pain is still one of the most frequently occurring symptoms at the end of life, although it can be treated satisfactorily in most cases if the physician has adequate knowledge [2-7].

\section{() Biomed Central}

(c) 2010 Rurup et al; licensee BioMed Central Ltd. This is an Open Access article distributed under the terms of the Creative Commons Attribution License (http://creativecommons.org/licenses/by/2.0), which permits unrestricted use, distribution, and reproduction in any medium, provided the original work is properly cited. 
Among countries, different physicians are involved in pain treatment at the end of life. In the Netherlands, health care is characterised by its strong emphasis on primary care, where the family physician is the central professional in the management and coordination of the patient's care [8]. Almost $60 \%$ of the patients with nonacute illnesses die at home where palliative care is coordinated by the general practitioner (GP) [9]. About 30\% of the patients with non-acute illnesses die in hospitals (cared for by clinical specialists), and about 10\% in nursing homes (where the elderly care physician - formerly known as nursing home physician - is responsible) [9]. It is estimated that $5 \%$ of all people die in a specialised palliative care unit. These units are part of nursing homes or homes for the elderly (50\%), or hospices $(50 \%)$ [10]. Characteristic for the Netherlands is that euthanasia is a legal option when suffering is unbearable and hopeless; in 2005, 1.7\% of all deaths was the result of euthanasia [11].

Elderly care physicians usually work in a single organisation, and are trained to care for elderly patients, including end of life care [12,13]. A wide range of clinical specialists provide end of life care in hospitals, and they also consult their colleagues in general practice and nursing homes to discuss complex symptoms in end of life care: for example $55 \%$ of the GPs cooperate with a clinical specialist [14]. In palliative home care, GPs frequently cooperate with district nurses [14] and can consult a regionally working palliative care consultation team [15].

In all these settings, possibilities to treat patients at the end of life with medication have increased in the past decade. Being able to take advantage of these possibilities does require physicians to maintain their knowledge. Guidelines that are developed by medical professional organizations can be a useful tool for this purpose.

Initially, there was optimism that the availability of evidence-based guidelines about pain management at the end of life would lead to great improvements in care. Research in the US showed that the problem of suboptimal pain management was far more complex than previously suspected: certain myths about the benefit of pain and the disadvantages and limitations of treatment of pain are to such an extent assimilated in the collective knowledge, that they are not banished by simply stating in a guideline that they are false [16]. Examples of such widespread myths are that pain often is inevitable, that administering increasing dosages of opioids hastens the end of life, and that adverse effects of opioids, such as drowsiness and confusion are inevitable [16-24].

In the international literature, the main focus of the effect of such myths is that opioids are underdosed, as a consequence of which patients may suffer needlessly $[16,20,21]$. Studies in the Netherlands have also shown that physicians treating cancer pain do not always follow evidence-based guidelines [25-27]. Another risk of myths can be that physicians overdose opioids, e.g. if they intend to hasten the end of life, and think they can attain this goal by increasing the dosage further than is required for pain management.

Developing and dispersing evidence-based guidelines is an important step towards an evidence-based practice, but further steps are required. To improve the quality of care at the end of life, it is subsequently necessary to study which knowledge has and which has not permeated to physicians, and which myths may hinder further permeation.

We aimed to study the level of knowledge of physicians, including both knowledge that should be familiar ground to all physicians, and facts that have more recently been added to the body of evidence, but should also be known to physicians involved in end of life care. Furthermore, we aimed to study experiences of physicians with pain management and opioids at the end of life, and possible barriers to good pain management at the end of life according to physicians.

\section{Methods}

Medical ethical approval was not necessary for this study in the Netherlands because it was a cross-sectional questionnaire study among physicians, patients were not involved and no interventions were done.

\section{Developing the questionnaire and the pilot study}

For this study, we developed a questionnaire to investigate knowledge and attitude concerning opioids and pain management at the end of life, based upon previous studies [19,20,28-34]. Questions were adapted and added to be able to answer the research questions, and to fit the specific situation in the Netherlands. For this purpose we used Dutch guidelines, original articles and review articles [17,22,23,35-53].

The questionnaire consisted of three types of questions: 1) knowledge statements with three answering options: "true", "false" and "don't know" 2) experience and attitude questions with five answering options: "completely agree", "agree more than disagree", "neutral", "disagree more than agree" and "completely disagree" and 3) other experience and attitude questions, partly structured with four answering options: "often", "sometimes", "seldom" and "never" and partly semistructured. Furthermore several background characteristics were asked, including to grade their own knowledge about opioids and pain management by scoring 1-10. After completing the knowledge statements, respondents were asked to again grade their own knowledge. 
The questionnaire was piloted among general practitioners in training $(\mathrm{n}=54)$ and elderly care physicians in training $(\mathrm{n}=24)$. Most physicians in the pilot indicated they used 15 minutes to complete the questionnaire. Opinions differed on the difficulty level of the knowledge statements in the questionnaire, but most physicians (79\%) did not think the statements were too difficult or they even thought they were (too) easy. The translated questionnaire is presented as an appendix in additional file 1.

\section{Sampling frame}

Physicians from the specialties which are most involved in pain management at the end of life were included in the random samples, namely: general practitioners, elderly care physicians, and clinical specialists specialized in internal medicine (incl oncologists, excl gastrointestinal and hepatic physicians), pulmonology, surgery (excl orthopaedics and plastic surgeons), cardiology, neurology, and anaesthesia. Geriatricians were not included in the sample as this is a small specialism in the Netherlands. The samples were randomly taken from different sources: general practitioners from the Netherlands Institute of Health Services Research (NIVEL), elderly care physicians from the Association of Physicians specialized in care for older people (Verenso) and clinical specialists from the medical address guide (BSL). These registrations consist of virtually all general practitioners, elderly care physicians and clinical specialists in the Netherlands. Including criteria were: currently working in the Netherlands as a physician, not in training.

\section{Data collection and anonymity}

The questionnaire was sent in January 2009. Two reminders were sent. The first reminder was a letter or an e-mail to remind them of the study, the second reminder included the questionnaire again and a short nonresponse questionnaire. Respondents could complete the questionnaire on paper or online. The written questionnaire was anonymous. A separate answer card with the personal data of the respondent could be mailed separately by the respondent to prevent further reminders. The online questionnaire was not anonymous, because it would otherwise not be possible to exclude the possibility that people who were not in the sample would complete the questionnaire. When the database was closed the questionnaires were made anonymous.

After the closing of the data collection, a document with the correct answers to the statements to test knowledge was sent by e-mail to the respondents who had indicated they were interested to receive this.

\section{Analysis}

All returned questionnaires were included in our analysis. Differences between non-responders and responders, and between general practitioners, elderly care physicians and clinical specialists were calculated using chi square tests. A significance level of $p<0.05$ was used. Answers "completely agree" and "agree more than disagree" were merged to the category "agree" when describing attitudes and experiences concerning pain, the prescription of opioids and consultation. A linear regression analysis was done with as a dependent variable the number of correct answers to the knowledge statements. The analysis was done backward stepwise until all independent variables had a $\mathrm{p}<0.05$ to construct a predictive model.

\section{Results}

\section{Background characteristics}

In Table 1 the background characteristics of the respondents are shown per specialty. Clinical specialists are employed full-time more often than general practitioners and elderly care physicians, and clinical specialists had most experience with prescribing opioids. Elderly care physicians had more experience with nonsudden deaths than clinical specialists and general practitioners and elderly care physicians had most often received a specific education in palliative care, apart from the regular medical education. Patients who were treated by the general practitioner at the moment of death were prescribed opioids more often than patients treated by clinical specialists or elderly care physicians at the moment of death.

\section{Response rate and non-response analysis}

In total 1044 physicians were sent a questionnaire, 55 envelopes were returned to sender, leaving 989 possible respondents. Of the 400 general practitioners, 182 completed the questionnaire (response rate 46\%), of the 175 elderly care physicians, 110 completed the questionnaire (response rate 63\%), and of the 414 clinical specialists, 112 completed the questionnaire (response rate 27\%), 2 physicians completed the questionnaire, without specifying their specialty. The total response rate was 406/989 $=41 \%$. Of the completed questionnaires, $80 \%$ was completed in writing and $20 \%$ was completed online. The non-response questionnaire was completed by 29 general practitioners, 6 elderly care physicians, and 43 clinical specialists.

There were several significant differences between physicians who completed the non-response questionnaire $(\mathrm{n}=78)$ and physicians who completed the full questionnaire $(\mathrm{n}=406)$ (not in Table). The nonresponse questionnaire was completed significantly more often by clinical specialists $(55 \%$ of the nonresponse questionnaires were completed by clinical specialists vs. $28 \%$ of the full questionnaires). Physicians who completed the non-response questionnaire were 


\section{Gender}

- Men

- Women

Age (years)

$\cdot<40$

$\cdot 41-50$

$\cdot 51-60$

$\cdot>60$

Employment

- full-time

- part-time

Grade given for own knowledge before completing the questionnaire (1-10)

$\cdot<5.5$

$\cdot 5.5-6.5$

$\cdot 6.6-7.5$

$\cdot 7.6-8.5$

- 8.6-10

Grade given for own knowledge after completing the questionnaire (1-10)

$\cdot<5.5$

$\cdot 5.5-6.5$

$\cdot 6.6-7.5$

$\cdot 7.6-8.5$

$\cdot 8.6-10$

Received specific education in palliative care apart from regular medical education

Number of patients to whom the respondent had prescribed opioids in $\mathbf{2 0 0 8}$

- None

$\cdot 1-5$

$\cdot 6-20$

$\cdot 21-50$

$$
\cdot>50
$$

Number of deaths after a sickbed (non-sudden) in 2008 while being treating physician

$$
\begin{aligned}
& \cdot \text { None } \\
& \cdot 1-5 \\
& \cdot \text { - 6-20 } \\
& \cdot 21-50 \\
& \cdot>50
\end{aligned}
$$

Percentage of these patients that were using opioids at the moment of death ${ }^{\ddagger}$

$$
\begin{aligned}
& \text { - None } \\
& \text { - 1-40\% } \\
& \text { - } 41-80 \% \\
& \text { - } 81-100 \%
\end{aligned}
$$

\begin{tabular}{l}
$\begin{array}{l}\text { General } \\
\text { practitioners }\end{array}$ \\
$\mathbf{n}=182$ \\
$\%$ \\
\hline
\end{tabular}

\section{Elderly care} physicians

$\mathrm{n}=110$

$\%$

63

36

20

32

41

7

7

54

43

43

\section{6}

36
65

31

33

35

1

27

$$
71
$$

\begin{tabular}{|c|c|c|}
\hline $\begin{array}{l}\text { Clinical } \\
\text { specialists }\end{array}$ & p-value* & Total \\
\hline$n=112$ & & $n=406^{\dagger}$ \\
\hline$\%$ & & $\%$ \\
\hline & $<0.05$ & \\
\hline 70 & & 58 \\
\hline 30 & & 42 \\
\hline
\end{tabular}

\begin{tabular}{|c|c|}
\hline 9 & 4 \\
\hline 15 & 11 \\
\hline 39 & 50 \\
\hline 29 & 30 \\
\hline 8 & 4 \\
\hline
\end{tabular}

$\geq 0.05$

$\begin{array}{lll}13 & 21 \\ 40 & 35 \\ 41 & 39 \\ 6 & & 5 \\ & <0.05 & \end{array}$

$\begin{array}{ll}80 & 55 \\ 20 & 45\end{array}$

$<0.05$

$<0.05$

$\begin{array}{ll} & 5 \\ & 12 \\ & 49 \\ & 32 \\ & 3 \\ <0.05 & 71\end{array}$

$\geq 0.05$

$\begin{array}{ll}2 & 3 \\ 2 & 13 \\ 28 & 24 \\ 46 & 2 \\ 21 & 42\end{array}$

3
13
24
20
42

13

$\begin{array}{llll}0 & 0 & 11 & 3 \\ 35 & 5 & 15 & 21 \\ 59 & 39 & 49 & 50 \\ 6 & 47 & 17 & 21 \\ 1 & 9 & 9 & 5 \\ & & & \\ 1 & 1 & 36.05 & \\ 17 & 16 & 42 & 2 \\ 46 & 66 & 14 & 22 \\ 37 & 17 & & 51 \\ \end{array}$

* chi-square test testing differences between the three groups of physicians † including 2 physicians who did not specify their specialty

\# percentage of patients per physician, (e.g. $37 \%$ of the general practitioners indicated that $81-100 \%$ of their patients were using opioids at the moment of death), percentages of physicians who had at least one death after a sickbed (non-sudden) in 2008 
significantly more often employed full-time than physicians who completed the full questionnaire $(80 \%$ vs. $55 \%)$, but had significantly less experience with prescribing opioids ( $85 \%$ vs. $99 \%$ in the past year) and with care at the end of life ( $84 \%$ vs. $97 \%$ in the past year). Furthermore, the full questionnaire was significantly more often completed by women than the non-response questionnaire. Finally, physicians who completed the nonresponse questionnaire rated their own knowledge of opioids and pain management on average somewhat lower than physicians who completed the full questionnaire (6.8 vs. 7.2$)$, but this difference was not statistically significant.

The most important reasons for non-response were "too busy", "no time" and "too many studies". Other reasons for non-response were lack of experience with care at the end of life in $18 \%$ and $12 \%$ thought they lacked the knowledge to complete the questionnaire.

\section{Knowledge statements}

In Table 2 the answers to the knowledge statements are shown per specialty. Of the 14 presented statements, general practitioners and elderly care physicians gave on average between 10 and 11 correct answers, clinical specialists gave on average between 9 and 10 correct answers. With statements 3, 6, 7, 9 and 10 more than $20 \%$ of the physicians marked that the statement was true when it was false, or the other way around. The answers of clinical specialists were significantly less often correct than the answers of general practitioners and/or elderly care physicians on the statements $1,2,9$ and 11-14.

\section{Attitudes concerning pain, the prescription of opioids and asking for advice}

The majority of the physicians (60\%) found good pain control in practice complex (Table 3 ). If physicians needed advice about pain management, they consulted their direct colleagues (74\%), their pharmacist $(53 \%)$ or the palliative care consultation team (not in Table). Most physicians did know of the availability of the consultation team (90\%), but $40 \%$ had never used it. The large majority (95\%) indicated they were open to unsolicited advice from the pharmacist.

The majority of the physicians (83\%) indicated that they combined opioids with a laxative. Clinical specialists did not see constipation often as a side-effect. Elderly care physicians indicated that it was not always possible to prescribe opioids to their patients because it was not necessary or because it would be too burdening.

The majority of the physicians (92\%) indicated that they did not combine opioids with an anti-emetic. Many physicians said they waited to see whether the patient developed nausea.
Attitudes and experiences concerning opioid rotation, tolerance, addiction and shortening of life by opioids Table 4 shows that in practice, clinical specialists less often rotate opioids than general practitioners and elderly care physicians (47\% versus $70 \%$ and $66 \%$ often or sometimes). A majority of all physicians (74\%), especially among clinical specialists (85\%) had sometimes or frequently experienced that tolerance could occur with the use of opioids, but less frequently thought tolerance hampered the usage of opioids in pain control (20\%).

Elderly care physicians experienced pressure from people around the patient to increase the opioids in the hope of hastening death significantly more often than general practitioners and clinical specialists (75\% vs. respectively $36 \%$ and $50 \%$ sometimes or often). One in 10 physicians at least sometimes increased the dosage of opioids above the level needed for pain and symptom control with the explicit aim to hasten the death of the patient. Clinical specialists and general practitioners did this more often than elderly care physicians (respectively $19 \%$ and $11 \%$ vs. $1 \%$, Table 4 ).

\section{Side-effects}

Most commonly observed side effect were constipation (observed $86 \%$ ), nausea (33\%), drowsiness (30\%), and delirium (9\%). Although less than $1 \%$ of the physicians reported often observing life-threatening respiratory depression, it was observed seldom by $61 \%$ of the clinical specialists. General practitioners (60\%) and elderly care physicians $(62 \%)$ said they never observed this possible side-effect.

\section{Education and self-knowledge vs. knowledge}

In Table 5 the relation is shown between education and the estimates of own knowledge vs. the number of correct answers to the 14 knowledge statements. Physicians who answered more knowledge statements correctly, had more often received specific training in palliative care.

Physicians who graded their own knowledge about pain management and opioids higher, answered more knowledge statements correctly. About a quarter of the physicians who answered one to nine of the knowledge statements correctly lowered their grade when asked again at the end of the questionnaire.

The majority of the physicians (83\%) would like to receive additional education about one or more subjects related to the end of life (not in Table). Almost half of the physicians (46\%) indicated they were interested in opioid rotation, pain- and symptom management in general $(44 \%)$, palliative sedation (30\%), pharmacological mechanism of opioids (18\%), side-effects (16\%), and other subjects $(5 \%)$. Some physicians who said there were not enough options for education said that 


\begin{tabular}{|c|c|c|c|c|c|c|}
\hline & & $\begin{array}{l}\text { General } \\
\text { practitioners }\end{array}$ & $\begin{array}{l}\text { Elderly } \\
\text { care } \\
\text { physicians }\end{array}$ & $\begin{array}{l}\text { Clinical } \\
\text { specialists }\end{array}$ & p-value ${ }^{\dagger}$ & Total \\
\hline & & $n=182$ & $n=110$ & $n=112$ & & $n=406$ \\
\hline \multirow{2}{*}{\multicolumn{2}{|c|}{ Average number of correct answers }} & 10,4 & 10,6 & 9,5 & & 10,2 \\
\hline & & $\%$ & $\%$ & $\%$ & & $\%$ \\
\hline \multicolumn{7}{|l|}{ Pain } \\
\hline $\begin{array}{l}\text { 1. In the management of pain it is important to differentiate } \\
\text { between nociceptive and neuropathic pain }\end{array}$ & $\begin{array}{l}\% \text { true } \\
\% \text { false } \\
\% \text { don't know }\end{array}$ & $\begin{array}{l}\mathbf{9 8} \\
1 \\
1\end{array}$ & $\begin{array}{l}100 \\
0 \\
0\end{array}$ & $\begin{array}{l}94 \\
0 \\
6\end{array}$ & $<0.05$ & $\begin{array}{l}97 \\
1 \\
2\end{array}$ \\
\hline $\begin{array}{l}\text { 2. Administration of opioids early on in the disease hampers good } \\
\text { pain control later on in the disease process }\end{array}$ & $\begin{array}{l}\% \text { true } \\
\% \text { false } \\
\% \text { don't know }\end{array}$ & $\begin{array}{l}3 \\
96 \\
2\end{array}$ & $\begin{array}{l}8 \\
91 \\
1\end{array}$ & $\begin{array}{l}10 \\
84 \\
6\end{array}$ & $<0.05$ & $\begin{array}{l}6 \\
91 \\
3\end{array}$ \\
\hline 3. Opioids may cause or worsen pain & $\begin{array}{l}\text { \% true } \\
\% \text { false } \\
\% \text { don't know }\end{array}$ & $\begin{array}{l}26 \\
45 \\
29\end{array}$ & $\begin{array}{l}34 \\
43 \\
23\end{array}$ & $\begin{array}{l}35 \\
43 \\
22\end{array}$ & $\geq 0.05$ & $\begin{array}{l}30 \\
45 \\
25\end{array}$ \\
\hline \multicolumn{7}{|l|}{ Prescribing opioids } \\
\hline $\begin{array}{l}\text { 4. Once opioids have been started, other analgesics should be } \\
\text { discontinued }\end{array}$ & $\begin{array}{l}\% \text { true } \\
\% \text { false } \\
\% \text { don't know }\end{array}$ & $\begin{array}{l}4 \\
96 \\
1\end{array}$ & $\begin{array}{l}1 \\
99 \\
0\end{array}$ & $\begin{array}{l}5 \\
92 \\
3\end{array}$ & $\geq 0.05$ & $\begin{array}{l}4 \\
96 \\
1\end{array}$ \\
\hline 5. Opioids are only indicated for cancer patients & $\begin{array}{l}\% \text { true } \\
\% \text { false } \\
\% \text { don't know }\end{array}$ & $\begin{array}{l}0 \\
100 \\
0\end{array}$ & $\begin{array}{l}0 \\
100 \\
0\end{array}$ & $\begin{array}{l}2 \\
98 \\
0\end{array}$ & $\geq 0.05$ & $\begin{array}{l}0 \\
100 \\
0\end{array}$ \\
\hline $\begin{array}{l}\text { 6. Simultaneous prescription of a weak opioid (e.g. tramadol) and a } \\
\text { strong opioid (e.g. morphine) is contra-indicated }{ }^{\mp}\end{array}$ & $\begin{array}{l}\% \text { true } \\
\% \text { false } \\
\% \text { don't know }\end{array}$ & $\begin{array}{l}49 \\
28 \\
22\end{array}$ & $\begin{array}{l}\mathbf{5 7} \\
26 \\
17\end{array}$ & $\begin{array}{l}\mathbf{5 7} \\
29 \\
14\end{array}$ & $\geq 0.05$ & $\begin{array}{l}\mathbf{5 4} \\
28 \\
19\end{array}$ \\
\hline $\begin{array}{l}\text { 7. Decreased renal function raises plasma concentration of morphine } \\
\text { (-metabolites) }\end{array}$ & $\begin{array}{l}\text { \% true } \\
\% \text { false } \\
\% \text { don't know }\end{array}$ & $\begin{array}{l}51 \\
22 \\
27\end{array}$ & $\begin{array}{l}55 \\
23 \\
22\end{array}$ & $\begin{array}{l}57 \\
23 \\
19\end{array}$ & $\geq 0.05$ & $\begin{array}{l}54 \\
22 \\
23\end{array}$ \\
\hline 8. Opioids have a maximum dosage & $\begin{array}{l}\% \text { true } \\
\% \text { false } \\
\% \text { don't know }\end{array}$ & $\begin{array}{l}4 \\
94 \\
2\end{array}$ & $\begin{array}{l}4 \\
93 \\
3\end{array}$ & $\begin{array}{l}8 \\
88 \\
4\end{array}$ & $\geq 0.05$ & $\begin{array}{l}5 \\
92 \\
3\end{array}$ \\
\hline \multicolumn{7}{|l|}{ Side-effects } \\
\hline $\begin{array}{l}\text { 9. Life-threatening respiratory depression is a real danger when } \\
\text { titrating morphine against pain }\end{array}$ & $\begin{array}{l}\% \text { true } \\
\% \text { false } \\
\% \text { don't know }\end{array}$ & $\begin{array}{l}16 \\
83 \\
2\end{array}$ & $\begin{array}{l}19 \\
75 \\
6\end{array}$ & $\begin{array}{l}31 \\
68 \\
1\end{array}$ & $<0.05$ & $\begin{array}{l}21 \\
77 \\
3\end{array}$ \\
\hline $\begin{array}{l}\text { 10. Drug management of nausea in treatment with opioids is } \\
\text { evidence-based }\end{array}$ & $\begin{array}{l}\% \text { true } \\
\% \text { false } \\
\% \text { don't know }\end{array}$ & $\begin{array}{l}40 \\
18 \\
42\end{array}$ & $\begin{array}{l}50 \\
12 \\
38\end{array}$ & $\begin{array}{l}34 \\
17 \\
50\end{array}$ & $\geq 0.05$ & $\begin{array}{l}41 \\
16 \\
43\end{array}$ \\
\hline \multicolumn{7}{|l|}{ Opioid rotation* } \\
\hline $\begin{array}{l}\text { 11. You want to change a daily dosage of } 60 \mathrm{mg} \text { oxycodon to a } \\
\text { fentanyl patch with an equivalent dosage. The strength of the patch } \\
\text { is.* }\end{array}$ & 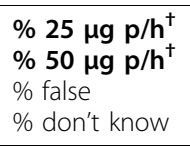 & $\begin{array}{l}28 \\
38 \\
6 \\
28\end{array}$ & $\begin{array}{l}37 \\
34 \\
12 \\
17\end{array}$ & $\begin{array}{l}25 \\
24 \\
11 \\
41\end{array}$ & $<0.05$ & $\begin{array}{l}30 \\
33 \\
9 \\
28\end{array}$ \\
\hline \multicolumn{7}{|l|}{ Sedation and shortening of life by opioids } \\
\hline 12. Opioids titrated against pain, shorten life & $\begin{array}{l}\% \text { true } \\
\% \text { false } \\
\% \text { don't know }\end{array}$ & $\begin{array}{l}3 \\
96 \\
1\end{array}$ & $\begin{array}{l}2 \\
95 \\
3\end{array}$ & $\begin{array}{l}14 \\
\mathbf{8 1} \\
6\end{array}$ & $<0.05$ & $\begin{array}{l}6 \\
91 \\
3\end{array}$ \\
\hline 13. Opioids are the favoured drugs for palliative sedation & $\begin{array}{l}\% \text { true } \\
\% \text { false } \\
\% \text { don't know }\end{array}$ & $\begin{array}{l}13 \\
86 \\
1\end{array}$ & $\begin{array}{l}5 \\
95 \\
0\end{array}$ & $\begin{array}{l}34 \\
57 \\
8\end{array}$ & $<0.05$ & $\begin{array}{l}17 \\
\mathbf{8 1} \\
3\end{array}$ \\
\hline 14. Opioids are appropriate drugs to perform euthanasia & $\begin{array}{l}\% \text { true } \\
\% \text { false } \\
\% \text { don't know }\end{array}$ & $\begin{array}{l}0 \\
99 \\
1\end{array}$ & $\begin{array}{l}0 \\
97 \\
3\end{array}$ & $\begin{array}{l}8 \\
86 \\
6\end{array}$ & $<0.05$ & $\begin{array}{l}2 \\
95 \\
3\end{array}$ \\
\hline
\end{tabular}

\footnotetext{
* correct answer is printed in bold.
}

${ }^{\dagger}$ chi-square test testing differences between the three groups of physicians.

‡ a simultaneous prescription of a weak and a strong opioid is not a contra-indication in the true sense of the word. It is, however, for pharmacodynamic reasons in general not a sensible combination. This is why it is not advocated in the available guidelines for treatment of pain.

** physicians could circle the following options 12/25/50/75/100/125/150 $\mu$ g per hour or "don't know". With this question 2 answers were considered correct, because different guidelines give different conversions, which leads to two different answers. 


\begin{tabular}{|c|c|c|c|c|c|}
\hline & $\begin{array}{l}\text { General } \\
\text { practitioners }\end{array}$ & $\begin{array}{l}\text { Elderly care } \\
\text { physicians }\end{array}$ & $\begin{array}{l}\text { Clinical } \\
\text { specialists }\end{array}$ & p-value* & Total \\
\hline & $n=182$ & $n=110$ & $n=112$ & & $n=406^{\dagger}$ \\
\hline & $\%$ agree & $\%$ agree & $\%$ agree & & $\%$ agree \\
\hline \multicolumn{6}{|l|}{ Pain } \\
\hline $\begin{array}{l}\text { - In case of a change in pain symptomatology, I always take a comprehensive } \\
\text { pain history }\end{array}$ & 74 & 64 & 73 & $\geq 0.05$ & 70 \\
\hline - In practice I find good pain control complex & 60 & 56 & 65 & $\geq 0.05$ & 60 \\
\hline - With the current medical possibilities, pain is always controllable & 21 & 26 & 29 & $\geq 0.05$ & 24 \\
\hline -When a patient is in pain, he/she will always indicate this & 16 & 8 & 17 & $\geq 0.05$ & 14 \\
\hline \multicolumn{6}{|l|}{ Prescribing opioids } \\
\hline $\begin{array}{l}\text { - When prescribing opioids, I always prescribe a maintenance dosage plus a } \\
\text { dosage to be used when needed (break-through medication) }\end{array}$ & 90 & 68 & 84 & $\geq 0.05$ & 80 \\
\hline - Nursing/care staff are reluctant to administer the opioids I prescribe & 4 & 4 & 10 & $\geq 0.05$ & 6 \\
\hline -I try to delay the prescription of opioids for as long as possible & 4 & 9 & 7 & $\geq 0.05$ & 6 \\
\hline \multicolumn{6}{|l|}{ Consultation } \\
\hline - Inadequate support from the pharmacist, hampers pain management & 7 & 8 & 3 & $\geq 0.05$ & 6 \\
\hline \multirow[t]{2}{*}{ - Asking for consultation feels like personal defeat } & 2 & 2 & 4 & $\geq 0.05$ & 2 \\
\hline & $\%$ yes & $\%$ yes & $\%$ yes & & $\%$ yes \\
\hline \multicolumn{6}{|l|}{ Laxative and anti-emetic } \\
\hline - As a general rule, I combine the prescription of an opioid with a laxative & 94 & 69 & 76 & $<0.05$ & 83 \\
\hline $\begin{array}{l}\text { - As a general rule, I combine the prescription of an opioid with an anti- } \\
\text { emetic }\end{array}$ & 8 & 2 & 13 & $\geq 0.05$ & 8 \\
\hline
\end{tabular}

offerings for education often came from the pharmaceutical industry, that education did not include the subjects they were interested in, that there was not a lot of education in the form of courses or that courses were not in their region. For the majority, the preferred way of education was symposia or conferences $(60 \%)$ and literature in Dutch journals (52\%).

\section{Linear regression analysis}

A linear regression analysis was done, with as the dependent variable the number of correct answers to the knowledge statements. Background characteristics and experience were included as independent variables: specialty of the physician (general practitioner/elderly care physician/clinical specialist), gender, year of graduation, full-time or part-time employment, specific education in palliative care, number of patients to whom opioids had been prescribed in the past year, number of patients who had died non-suddenly in the past year. The resulting model $\left(R^{2}=0.16\right)$ showed that more experience with prescribing opioids and having received a specific education in palliative care have a positive influence on the number of correctly answered knowledge statements. Furthermore the variable "clinical specialist"(vs. general practitioner and elderly care physician) had an independent negative influence on the number of correctly answered statements. Finally, men answered less statements correctly than women did. (Table 6).

\section{Discussion}

Studying the knowledge level of physicians concerning pain management presents a number of challenges, because pain management is not a "hard science". It cannot be mastered by knowing a number of facts, but this method of study only allows for testing such facts. We have limited the knowledge statements almost exclusively to knowledge about which consensus has been reached and which is incorporated in pain management guidelines. Even then, it is difficult to make true or false statements. Physicians' whose answer is considered 'wrong' may have good reasons to think their answer is correct. We cannot set a limit of the number of statements that should be answered correctly to be an adequate physician.

We can conclude that several statements were answered correctly by the majority of the physicians. In our study physicians answered on average 10 out of 14 knowledge statements correctly (71\%). In various studies physicians scored between $31 \%$ and $68 \%$ correct answers $[29,30,54]$, although the overall scores in different studies cannot be compared as such because other statements were used. 
Table 4 Attitudes and experiences concerning opioid rotation*, tolerance**, addiction and shortening of life by opioids

\begin{tabular}{|c|c|c|c|c|c|}
\hline & $\begin{array}{l}\text { General } \\
\text { practitioners }\end{array}$ & Elderly care & $\begin{array}{l}\text { Clinical } \\
\text { specialists }\end{array}$ & p-value $^{\dagger}$ & Total \\
\hline & $n=182$ & $n=110$ & $n=112$ & & $n=406^{\dagger}$ \\
\hline & $\begin{array}{l}\text { \%often/ } \\
\text { sometimes }\end{array}$ & $\begin{array}{l}\text { \%often/ } \\
\text { sometimes }\end{array}$ & $\begin{array}{l}\text { \%often/ } \\
\text { sometimes }\end{array}$ & & $\begin{array}{l}\text { \%often/ } \\
\text { sometimes }\end{array}$ \\
\hline \multicolumn{6}{|l|}{ Opioid rotation* } \\
\hline - I rotate opioids in practice & 70 & 66 & 47 & $<0.05$ & 62 \\
\hline - I rotate opioids if pain control is inadequate & 77 & 72 & 65 & $\geq 0.05$ & 72 \\
\hline - I rotate opioids in case of side-effects & 67 & 73 & 63 & $\geq 0.05$ & 67 \\
\hline - I find calculating of opioid dosages when rotating difficult & 62 & 57 & 57 & $\geq 0.05$ & 59 \\
\hline \multicolumn{6}{|l|}{ Tolerance** and fear of addiction } \\
\hline - I have noticed that tolerance can develop in the usage of opioids & 68 & 74 & 85 & $<0.05$ & 74 \\
\hline - Tolerance hampers the usage of opioids in pain control & 15 & 20 & 29 & $<0.05$ & 20 \\
\hline - Patients' fear of addiction hampers the usage of opioids in practice & 49 & 35 & 51 & $<0.05$ & 46 \\
\hline \multicolumn{6}{|l|}{ Shortening of life by opioids } \\
\hline $\begin{array}{l}\text { - It occurs that relatives of a patient or other persons concerned, put } \\
\text { pressure on me to increase the opioids in the hope of hastening death }\end{array}$ & 36 & 75 & 50 & $<0.05$ & 50 \\
\hline $\begin{array}{l}\text { - When titrating the dosage of opioids upwards against pain, I take into } \\
\text { account that this may hasten the death of the patient }\end{array}$ & 38 & 44 & 68 & $<0.05$ & 48 \\
\hline $\begin{array}{l}\text { - It occurs that I increase the dosage of opioids to a level above that of } \\
\text { what is needed for pain and symptom control with the explicit aim to } \\
\text { hasten the death of the patient }\end{array}$ & 11 & 1 & 19 & $<0.05$ & 10 \\
\hline \multicolumn{6}{|c|}{$\begin{array}{l}\text { * The following definition of tolerance was given in the questionnaire: "By tolerance for a drug we mean that a patient needs a higher dose to reach the same } \\
\text { pain relief while the pain stimulus remains the same. Tolerance has proven to be difficult to measure in practice, we are interested in your personal experience." }\end{array}$} \\
\hline \multicolumn{6}{|c|}{${ }^{\dagger}$ chi-square test testing differences between the three groups of physicians. } \\
\hline${ }^{\ddagger}$ including 2 physicians who did not specify their specialty. & & & & & \\
\hline
\end{tabular}

We also identified some points where there was lack of knowledge in a considerable part of the physicians. E.g. less than one in three physicians was aware that opioids may cause or worsen pain. Although this is a rare effect the clinical effects can be significant if the dose of opioids is increased instead of decreased when a patient suffers from opioid-induced pain sensitivity [39-42]. There also seemed to be a lack of awareness that decreased renal function raises plasma concentration of morphine(-metabolites). If a patient has decreased renal function, certain opioids are preferred above others, to prevent side-effects $[55,56]$. It is also crucial that physicians involved in end of life care are aware that opioids are not the drug of choice for palliative sedation. More than one in three clinical specialists thought that opioids are the favoured drugs for palliative sedation. According to Dutch guidelines for palliative sedation, sedation with opioids should be considered malpractice [53].

\section{Hastening the end of life}

Although the majority of the general practitioners and the elderly care physicians said they had never experienced life-threatening respiratory depression as a side- effect of opioids, part of the general practitioners and elderly care physicians (respectively 16\% and 19\%) did think this was a real danger, even when titrated against pain. Among clinical specialists even a third thought this was a real danger, although many studies have shown that this is not the case [22,23,49-53]. However, this knowledge seems to conflict with practice as $48 \%$ of all physicians take hastening of the patient's death into account when titrating opioids. And it appears that physicians act upon this misconception: $19 \%$ of the clinical specialists and $11 \%$ of the general practitioners indicated that they increased the dosage of opioids to a level above what is needed for pain and symptom control with the explicit aim to hasten the death of the patient.

A surprisingly large percentage of the elderly care physicians (75\%) did feel pressured sometimes or often by relatives of a patient or other persons to increase the dosage of opioids in the hope of hastening death. Possibly this is related to the fact that elderly care physicians often care for patients with dementia who are unable to discuss medical decisions with their physician.

This result illustrates that good care at the end of life is more comprehensive than prescribing the right (dosage of) drugs. Contact and communication with 
Table 5 Relation between education and the estimates of own knowledge vs. the number of correct answers to the 14 knowledge statements

\begin{tabular}{|c|c|c|c|c|c|}
\hline & $\begin{array}{l}3-9 \text { correct } \\
\text { answers } \\
\mathrm{N}=114 \\
\%\end{array}$ & $\begin{array}{l}10 \text { correct } \\
\text { answers } \\
\mathrm{N}=95 \\
\%\end{array}$ & $\begin{array}{l}11 \text { correct } \\
\text { answers } \\
\mathrm{N}=105 \\
\%\end{array}$ & $\begin{array}{l}12-14 \text { correct } \\
\text { answers } \\
\mathrm{N}=93 \\
\%\end{array}$ & p-value* \\
\hline Received specific education in palliative care & 60 & 68 & 78 & 87 & $<0.05$ \\
\hline $\begin{array}{l}\text { Grade given for own knowledge before completing the } \\
\text { questionnaire }(1-10)^{\dagger}\end{array}$ & & & & & $<0.05$ \\
\hline$\cdot<5.5$ & 11 & 1 & 1 & 3 & \\
\hline$\cdot 5.5-6.5$ & 19 & 11 & 10 & 5 & \\
\hline$\cdot 6.6-7.5$ & 46 & 60 & 51 & 46 & \\
\hline$\cdot 7.6-8.5$ & 20 & 27 & 34 & 41 & \\
\hline$\cdot 8.6-10$ & 5 & 1 & 5 & 4 & \\
\hline $\begin{array}{l}\text { Grade given for own knowledge after completing the } \\
\text { questionnaire }(1-10)^{\dagger}\end{array}$ & & & & $\geq 0.05$ & $<0.05$ \\
\hline$\cdot<5.5$ & 11 & 1 & 3 & 2 & \\
\hline$\cdot 5.5-6.5$ & 24 & 6 & 8 & 6 & \\
\hline$\cdot 6.6-7.5$ & 48 & 61 & 50 & 41 & \\
\hline$\cdot 7.6-8.5$ & 15 & 32 & 37 & 46 & \\
\hline$\cdot 8.6-10$ & 2 & 0 & 4 & 6 & \\
\hline $\begin{array}{l}\text { Are there enough options for you for additional education about } \\
\text { opioids and pain management? }\end{array}$ & & & & & $<0.05$ \\
\hline - Yes & 77 & 94 & 93 & 95 & \\
\hline - No & 23 & 6 & 7 & 5 & \\
\hline
\end{tabular}

* chi square test to test differences in physician characteristics for physicians with different numbers of correct answers (categorized in 4 groups).

${ }^{\dagger}$ Physicians graded their own knowledge about opioids and pain management by scoring 1-10. After completing the knowledge statements, respondents were asked to again grade their own knowledge. Physicians could not see how they did on the knowledge statements, they did not receive the answers to the knowledge statements immediately after completing the questionnaire.

relatives are crucial in palliative care. It also shows that the misconception that high dosages of opioids hasten the end of life probably also exists among relatives and patients. In practice, only an overdose of opioids could hasten the end of life. Even then hastening death is not likely, but there is an increased risk of serious side-effects, such as a delirium [22,23,49-53]. For that reason the Dutch guideline about euthanasia drugs states that not opioids but barbiturates followed by neuromuscular relaxants are to be used for euthanasia [57]. Nevertheless, this study shows that $8 \%$ of the clinical specialists does think opioids are appropriate drugs for euthanasia.
However, it seems that the proportion of physicians acting upon this misconception is decreasing the last years. The proportion of opioids as drugs in euthanasia deaths has decreased from $21.6 \%$ in 2001 to $16.2 \%$ in 2005 [11], making it likely that the knowledge of opioids in end of life has increased.

\section{Opioid rotation}

Rotation of opioids means that one opioid is substituted by another. This can be done in case of inadequate pain management or in case of side-effects. A quarter of the clinical specialists said they never rotated opioids. Many physicians said they had difficulties calculating opioid

Table 6 Physician characteristics related to the number of correct answers on the knowledge statements (multivariate linear regression; $n=406$ )

\begin{tabular}{llll}
\hline Dependent variable & Independent variables* & $\begin{array}{l}\text { Beta (standardised regression } \\
\text { coefficient) }\end{array}$ & p \\
\hline - Number of correct answers on the & - Number of patients to whom the respondent & .22 & $<0.001$ \\
knowledge statements & prescribes opioids per year & .18 & $<0.001$ \\
& - Received specific education in palliative care & -.16 & $<0.001$ \\
& - Clinical Specialist & -.10 & 0.03 \\
& - Man & & \\
\hline
\end{tabular}

* variables that were analysed, but were not significant in the final model: year of graduation, full-time or part-time employment, number of patients that had died non-suddenly in the past year 
dosages when rotating (59\%) and many physicians were interested in education about opioid rotation (46\%). The evidence for equianalgesic conversion rates is limited, and equianalgesic doses vary among individuals under varying conditions [58]. Clinical characteristics such as organ dysfunction and age influence pharmacokinetics and pharmacodynamics. Scientific insights are developing and sometimes conflicting - for example concerning the influence of age on pharmacokinetics of transdermal fentanyl $[59,60]$. This might explain why standards mention different equianalgesic conversions for opioids. Two current Dutch guidelines present different conversion factors for some types of opioids. The cause of this difference is unclear; possibly there is no evidence to formulate unambiguous conversion factors. As a result of this, the knowledge statement about opioid rotation in this study has two possible answers. In our analyses, both answers were considered correct. In practice the reason for rotation is also relevant for the conversion factor: in case of rotation because of side-effects, it is recommended to convert to a lower than equivalent dose, in case of rotation because of inadequate pain relief it is recommended to rotate to an equivalent dose.

\section{Asking for advice and education}

Physicians had on average reasonable knowledge about their own knowledge level. However, part of the physicians who did not answer many knowledge statements correct, did think their knowledge was adequate. It is important that physicians know their limits, so they know when to ask for assistance.

A remarkable high number of physicians (83\%) was interested in additional education about opioids or pain management. It seems there are enough options for additional education in the Netherlands, but that this does not always fit the wishes of the physicians. Physicians were interested in efficient, objective education, preferably by parties other than the pharmaceutical industry.

\section{Strengths and limitations of this study}

A strength of this study is that it is the first study in the Netherlands which has mapped the knowledge level of physicians about the use of opioids and pain management at the end of life. It has highlighted some important gaps in the knowledge of Dutch physicians. The results can be useful to improve (additional) education, which is necessary to improve the quality of care at the end of life. The statements used in this study can also be used for training purposes, and in studies in other countries with the same objectives as this study.

A limitation of this study is that only a limited number of themes are highlighted in which physicians should have adequate knowledge, and within those themes, not all aspects can be studied. Other limitations are that the response rate is moderate, and that the questionnaire has not been validated, although the pilot study did not reveal questions or answer categories that were not understood by the respondents. Hence, the answer category 'don't know' should be interpreted as physicians that did not know the answer to the question. Physicians who participated in this study, assessed their own knowledge somewhat higher than physicians who answered the nonresponse questionnaire, so probably this study tends to give a too positive image of the knowledge of physicians rather than a too negative image. It is possible that the knowledge about opioids and attitudes differ also within the three groups of physicians, as a result of different clinical specialty or experience in palliative care. We did not analyse possible differences, as we did not design our study to investigate these.

\section{Conclusions}

Although the effects of a gap in the knowledge about opioids on the clinical practice differ per subject, we can conclude that most of the knowledge questioned in our study should be part of the basal knowledge physicians should have, and that a gap in this knowledge can be a barrier for adequate care at the end of life. Good care at the end of life is more comprehensive than adequate knowledge about pain management, but this is an essential part of it.

From this study -including physicians' attitudes and opinions as well as a test of their knowledge- three areas emerge, in which it seems likely that an improvement in these areas can improve the quality of pain management at the end of life for many patients in the Netherlands, namely: 1) palliative sedation, opioids are too often erroneously considered the appropriate drug for palliative sedation; 2) hastening the end of life with opioids, opioids are too often erroneously thought to shorten life, even when titrated against pain; 3 ) opioid rotation, opioid rotation is considered a difficult area by the majority of physicians, in which they would like additional education.

\section{Additional material}

Additional file 1: Appendix 1 questionnaire. An English translation of the study questionnaire

\footnotetext{
Acknowledgements

This study was supported by grants from the Platform Palliative Care from the Dutch ministry of Health and the Comprehensive Cancer Centre Amsterdam (IKA).

The funders granted the research proposal as offered by the researchers and they provided the funds. They had no further role in the study.
} 
The knowledge statements presented in this article can be freely used for research or training purposes. Please reference the source and send a notification to the corresponding author.

\section{Author details}

${ }^{1}$ VU University Medical Center, EMGO Institute for Health and Care Research, Department of Public and Occupational Health, Amsterdam, The Netherlands. ${ }^{2} \mathrm{VU}$ University Medical Center, Palliative Care Center of Expertise, Amsterdam, The Netherlands. ${ }^{3} \mathrm{VU}$ University Medical Center, Department of Medical Oncology, Palliative Care Consultation team, Amsterdam, The Netherlands. ${ }^{4} \mathrm{VU}$ University Medical Center, Department of Clinical Pharmacology and Pharmacy, Amsterdam, The Netherlands. ${ }^{5}$ Department of Clinical Pharmacy, Academic Medical Center, Amsterdam, The Netherlands.

\section{Authors' contributions}

MLR was involved in conception and design of the study, acquisition of data, analysis and interpretation of data, drafting of the manuscript and revision. CAR was involved in design of the study, acquisition of data, interpretation of data, revising of the manuscript. SDB was involved in conception and design of the study, analysis and interpretation of data, revising of the manuscript, drafting the revision. MSAB was involved in conception and design of the study, interpretation of data, revising of the manuscript. AGMK was involved in acquisition of data, analysis of data, revising of the manuscript. HRWP was involved in conception and design of the study, interpretation of data, revising of the manuscript. BDOP was involved in conception and design of the study, interpretation of data, revising of the manuscript, drafting the revision. All authors read and approved the final manuscript.

\section{Authors' information}

MLR works as a senior researcher in the subject of end of life studies at the VU University Medical Center, EMGO Institute for Health and Care Research, Department of Public and Occupational Health.

CAR works as an elderly care physician, and at the time of the study, worked at the VU University Medical Center, Department of Medical Oncology, Palliative Care Consultation team.

MSAB works as a hospice physician, and at the time of the study, worked at the VU University Medical Center, Department of Medical Oncology, Palliative Care Consultation team.

AGMK works as a junior researcher at the VU University Medical Center EMGO Institute for Health and Care Research, Department of Public and Occupational Health.

SDB works as a pharmacist at the Department of Clinical Pharmacy of the Academic Medical Center and at the time of the study as a researcher at the Department of Clinical Pharmacology and Pharmacy of the VU University Medical Center

HRWP works as a senior researcher in the subject of end of life studies at the VU University Medical Center, EMGO Institute for Health and Care Research, Department of Public and Occupational Health. BDOP works as a professor in end-of-life research at the VU University Medical Center, EMGO Institute for Health and Care Research, Department of Public and Occupational Health.

\section{Competing interests}

The authors declare that they have no competing interests.

Received: 9 April 2010 Accepted: 12 November 2010 Published: 12 November 2010

\section{References}

1. Fairchild A: Under-treatment of cancer pain. Curr Opin Support Palliat Care 2010, 4:11-15.

2. Potter J, Hami F, Bryan T, Quigley C: Symptoms in $\mathbf{4 0 0}$ patients referred to palliative care services: prevalence and patterns. Palliat Med 2003, 17:310-314.

3. Teunissen SC, Wesker W, Kruitwagen C, de Haes HC, Voest EE, de Graeff A: Symptom prevalence in patients with incurable cancer: a systematic review. J Pain Symptom Manage 2007, 34:94-104.

4. Borgsteede SD, Deliens L, Beentjes B, Schellevis F, Stalman WA, van Eijk JT, Van der Wal G: Symptoms in patients receiving palliative care: a study on patient-physician encounters in general practice. Palliat Med 2007, 21:417-423.

5. Grossman SA, Dunbar EM, Nesbit SA: Cancer pain management in the 21st century. Oncology (Williston Park) 2006, 20:1333-1339.

6. Enting RH, Oldenmenger WH, Van Gool AR, van der Rijt CC, Sillevis Smitt PA: The effects of analgesic prescription and patient adherence on pain in a dutch outpatient cancer population. J Pain Symptom Manage 2007, 34:523-531.

7. Teno JM, Clarridge BR, Casey V, Welch LC, Wetle T, Shield R, Mor V: Family perspectives on end-of-life care at the last place of care. JAMA 2004, 291:88-93.

8. Health Council of the Netherlands: European primary care. The Hague: Health Council of the Netherlands; $20 \mathrm{E} 2004$.

9. Francke AL, Willems DL: Palliatieve zorg vandaag en morgen. [Palliative care today and tomorrow]. Maarssen: Elsevier gezondheidszorg; 12000.

10. Mistiaen P, Van Ruth L, Francke AL: Monitor Palliatieve Zorg [Monitor Palliative Care]. Utrecht: NIVEL; 2006.

11. Van der Heide A, Onwuteaka-Philipsen BD, Rurup ML, Buiting HM, van Delden JJ, Hanssen-de Wolf JE, Janssen AG, Pasman HR, Rietjens JA, Prins CJ, Deerenberg IM, Gevers JK, van der Maas PJ, Van der Wal G: Endof-life practices in the Netherlands under the Euthanasia Act. N EnglJ Med 2007, 356:1957-1965.

12. Ribbe MW, Ljunggren G, Steel K, Topinkova E, Hawes C, Ikegami N, Henrard JC, Jonnson PV: Nursing homes in 10 nations: a comparison between countries and settings. Age Ageing 1997, 26(Suppl 2):3-12.

13. Brandt HE, Deliens L, Ooms ME, van der Steen JT, Van der Wal G, Ribbe MW: Symptoms, signs, problems, and diseases of terminally ill nursing home patients: a nationwide observational study in the Netherlands. Arch Intern Med 2005, 165:314-320.

14. Borgsteede SD, Deliens L, Van der Wal G, Francke AL, Stalman WA, van Eijk JT: Interdisciplinary cooperation of GPs in palliative care at home: a nationwide survey in The Netherlands. Scand J Prim Health Care 2007, 25:226-231.

15. Kuin $A$, Courtens $A M$, Deliens $L$, Vernooij-Dassen $M J$, van Zuylen $L$, van der Linden B, Van der Wal G: Palliative care consultation in The Netherlands: a nationwide evaluation study. J Pain Symptom Manage 2004, 27:53-60.

16. Carr DB: The development of national guidelines for pain control: synopsis and commentary. Eur J Pain 2001, 5(Suppl A):91-98.

17. McQuay H: Opioids in pain management. Lancet 1999, 353:2229-2232.

18. Estfan B, Mahmoud F, Shaheen P, Davis MP, Lasheen W, Rivera N, Legrand SB, Lagman RL, Walsh D, Rybicki L: Respiratory function during parenteral opioid titration for cancer pain. Palliat Med 2007, 21:81-86.

19. Elliott TE, Elliott BA: Physician attitudes and beliefs about use of morphine for cancer pain. J Pain Symptom Manage 1992, 7:141-148.

20. Whipple JK, Lewis KS, Quebbeman EJ, Wolff M, Gottlieb MS, MedicusBringa M, Hartnett KR, Graf M, Ausman RK: Analysis of pain management in critically ill patients. Pharmacotherapy 1995, 15:592-599.

21. Hanks GW, Conno F, Cherny N, Hanna M, Kalso E, McQuay HJ, Mercadante S, Meynadier J, Poulain P, Ripamonti C, Radbruch L, Casas JR, Sawe J, Twycross RG, Ventafridda V: Morphine and alternative opioids in cancer pain: the EAPC recommendations. Br J Cancer 2001, 84:587-593.

22. Sykes $N$, Thorns A: The use of opioids and sedatives at the end of life. Lancet Oncol 2003, 4:312-318.

23. Vitetta $L$, Kenner $D$, Sali A: Sedation and analgesia-prescribing patterns in terminally ill patients at the end of life. Am J Hosp Palliat Care 2005, 22:465-473.

24. Gallagher R, Hawley P, Yeomans W: A survey of cancer pain management knowledge and attitudes of British Columbian physicians. Pain Res Manag 2004, 9:188-194.

25. Rurup ML, Borgsteede SD, Van der Heide A, van der Maas PJ, OnwuteakaPhilipsen BD: Trends in the Use of Opioids at the End of Life and the Expected Effects on Hastening Death. J Pain Symptom Manage 2009, 37:144-55.

26. Bouvy ML, Buurma H, Egberts TC: Laxative prescribing in relation to opioid use and the influence of pharmacy-based intervention. $J$ Clin Pharm Ther 2002, 27:107-110.

27. Borgsteede SD, Deliens L, Zuurmond WW, Schellevis FG, Willems DL, Van der Wal G, van Eijk JT: Prescribing of pain medication in palliative care. A survey in general practice. Pharmacoepidemiol Drug Saf 2009, 18:16-23. 
28. Niemi-Murola L, Nieminen JT, Kalso E, Poyhia R: Medical undergraduate students' beliefs and attitudes toward pain: how do they mature? Eur $\mathrm{J}$ Pain 2007, 11:700-706.

29. Vallerand AH, Collins-Bohler D, Templin T, Hasenau SM: Knowledge of and barriers to pain management in caregivers of cancer patients receiving homecare. Cancer Nurs 2007, 30:31-37.

30. Lambert K, Oxberry S, Hulme CW, Saharia K, Rigby AS, Johnson MJ: Knowledge of attitudes to opioids in palliative care patients. Palliat Med 2007, 21:721-722.

31. Bosch F, Banos JE: Religious beliefs of patients and caregivers as a barrier to the pharmacologic control of cancer pain. Clin Pharmacol Ther 2002, 72:107-111.

32. Potter M, Schafer S, Gonzalez-Mendez E, Gjeltema K, Lopez A, Wu J, Pedrin R, Cozen M, Wilson R, Thom D, Croughan-Minihane M: Opioids for chronic nonmalignant pain. Attitudes and practices of primary care physicians in the UCSF/Stanford Collaborative Research Network. University of California, San Francisco. J Fam Pract 2001, 50:145-151.

33. Hollen CJ, Hollen CW, Stolte K: Hospice and hospital oncology unit nurses: a comparative survey of knowledge and attitudes about cancer pain. Oncol Nurs Forum 2000, 27:1593-1599.

34. Larue F, Fontaine A, Brasseur L: Evolution of the French public's knowledge and attitudes regarding postoperative pain, cancer pain, and their treatments: two national surveys over a six-year period. Anesth Analg 1999, 89:659-664.

35. de Leon-Casasola OA: Current developments in opioid therapy for management of cancer pain. Clin J Pain 2008, 24(Suppl 10):S3-S7.

36. Cherny N, Ripamonti C, Pereira J, Davis C, Fallon M, McQuay H, Mercadante S, Pasternak G, Ventafridda V: Strategies to manage the adverse effects of oral morphine: an evidence-based report. $J$ Clin Oncol 2001, 19:2542-2554.

37. Grond S, Radbruch L, Meuser T, Sabatowski R, Loick G, Lehmann KA: Assessment and treatment of neuropathic cancer pain following $\mathrm{WHO}$ guidelines. Pain 1999, 79:15-20.

38. Thompson AR, Ray JB: The importance of opioid tolerance: a therapeutic paradox. J Am Coll Surg 2003, 196:321-324.

39. Angst MS, Clark JD: Opioid-induced hyperalgesia: a qualitative systematic review. Anesthesiology 2006, 104:570-587.

40. Mao J: Opioid-induced abnormal pain sensitivity: implications in clinical opioid therapy. Pain 2002, 100:213-217.

41. Davis MP, Shaiova LA, Angst MS: When opioids cause pain. J Clin Oncol 2007, 25:4497-4498.

42. Mercadante S, Ferrera P, Villari P, Arcuri E: Hyperalgesia: an emerging iatrogenic syndrome. J Pain Symptom Manage 2003, 26:769-775.

43. Davis MP, Lasheen W, Gamier P: Practical guide to opioids and their complications in managing cancer pain. What oncologists need to know. Oncology (Williston Park) 2007, 21:1229-1238.

44. Marcou TA, Marque S, Mazoit JX, Benhamou D: The median effective dose of tramadol and morphine for postoperative patients: a study of interactions. Anesth Analg 2005, 100:469-474.

45. Hagle ME, Lehr VT, Brubakken K, Shippee A: Respiratory depression in adult patients with intravenous patient-controlled analgesia. Orthop Nurs 2004, 23:18-27.

46. Macintyre PE: Safety and efficacy of patient-controlled analgesia. $\mathrm{Br} J$ Anaesth 2001, 87:36-46.

47. Ko S, Goldstein DH, VanDenKerkhof EG: Definitions of "respiratory depression" with intrathecal morphine postoperative analgesia: a review of the literature. Can J Anaesth 2003, 50:679-688.

48. Glare P, Pereira G, Kristjanson $\sqcup$, Stockler M, Tattersall M: Systematic review of the efficacy of antiemetics in the treatment of nausea in patients with far-advanced cancer. Support Care Cancer 2004, 12:432-440.

49. Thorns A, Sykes $\mathrm{N}$ : Opioid use in last week of life and implications for end-of-life decision-making. Lancet 2000, 356:398-399.

50. Morita T, Tsunoda J, Inoue S, Chihara S: Effects of high dose opioids and sedatives on survival in terminally ill cancer patients. J Pain Symptom Manage 2001, 21:282-289.

51. Bercovitch M, Adunsky A: Patterns of high-dose morphine use in a homecare hospice service: should we be afraid of it? Cancer 2004, 101:1473-1477.

52. Good PD, Ravenscroft PJ, Cavenagh J: Effects of opioids and sedatives on survival in an Australian inpatient palliative care population. Intern Med J 2005, 35:512-517.
53. Commissie landelijke richtlijn palliatieve sedatie: KNMG richtlijn "Palliatieve sedatie". 2009.

54. Elliott TE, Murray DM, Elliott BA, Braun B, Oken MM, Johnson KM, PostWhite J, Lichtblau L: Physician knowledge and attitudes about cancer pain management: a survey from the Minnesota cancer pain project. J Pain Symptom Manage 1995, 10:494-504.

55. Mercadante S, Arcuri E: Opioids and renal function. J Pain 2004, 5:2-19.

56. Arnold RM, Verrico P, Davison SN: Opioid use in renal failure \#161. J Palliat Med 2007, 10:1403-1404.

57. KNMP/WINAp: Standaard Euthanatica. Toepassing en bereiding [Standard for Euthanatics. Preparation and use]. Den Haag: KNMP; 2007.

58. Knotkova H, Fine PG, Portenoy RK: Opioid rotation: the science and the limitations of the equianalgesic dose table. J Pain Symptom Manage 2009, 38:426-439.

59. Holdsworth MT, Forman WB, Killilea TA, Nystrom KM, Paul R, Brand SC, Reynolds R: Transdermal fentanyl disposition in elderly subjects. Gerontology 1994, 40:32-37.

60. Gupta SK, Hwang S, Southam M, Sathyan G: Effects of application site and subject demographics on the pharmacokinetics of fentanyl $\mathrm{HCl}$ patientcontrolled transdermal system (PCTS). Clin Pharmacokinet 2005, 44(Suppl 1):25-32.

\section{Pre-publication history}

The pre-publication history for this paper can be accessed here: http://www.biomedcentral.com/1472-684X/9/23/prepub

doi:10.1186/1472-684X-9-23

Cite this article as: Rurup et al:: The use of opioids at the end of life: the knowledge level of Dutch physicians as a potential barrier to effective pain management. BMC Palliative Care 2010 9:23.

\section{Submit your next manuscript to BioMed Central and take full advantage of:}

- Convenient online submission

- Thorough peer review

- No space constraints or color figure charges

- Immediate publication on acceptance

- Inclusion in PubMed, CAS, Scopus and Google Scholar

- Research which is freely available for redistribution 